\title{
Stop adding insult to injury_-identifying and managing risk factors for the progression of acute kidney injury in children
}

\author{
Wesley Hayes ${ }^{1,2}$ (D)
}

Received: 31 October 2016 /Revised: 13 January 2017 / Accepted: 13 January 2017 /Published online: 15 February 2017

(C) The Author(s) 2017. This article is published with open access at Springerlink.com

\begin{abstract}
Acute kidney injury (AKI) is common in children admitted to hospital. Whilst some recover normal kidney function following an acute kidney insult, a significant proportion experience long-term sequelae. The aim of this review is to summarize current understanding of the processes that can lead to sequelae following AKI. Kidney injury, repair, recovery and progression are described. Risk factors for progression are outlined, and potential strategies to stratify the risk of progression in children with AKI are discussed. Clinical management priorities to minimize sequelae are suggested. Looking ahead, novel therapeutic targets are discussed with the potential to accelerate adaptive repair and ameliorate the progression and sequelae of AKI in the future.
\end{abstract}

Keywords AKI · Children · Progression · CKD · Hypertension

\section{Introduction}

The incidence of acute kidney injury (AKI) in children is rising. One in three children worldwide experience AKI during an episode of hospital care [1]. Most children are exposed to AKI risk factors, such as medication with nephrotoxic potential, during a hospital stay [2,3]. To date, initiatives have rightly prioritized improving the identification and initial management of AKI with global awareness-raising campaigns and

Wesley Hayes

Wesley.Hayes@gosh.nhs.uk

1 Great Ormond Street Hospital for Children, London, UK

2 University College London, London, UK national and international diagnosis and management guidelines [4-6]. The events that follow AKI have received less attention.

Traditionally, AKI in children had been understood to be an entirely reversible phenomenon. In recent years, this customary view has been challenged by emerging evidence that supports a strong link between AKI and chronic kidney disease (CKD) in adult patients [7]. In this review, current understanding of the events that follow acute kidney insults in children is outlined, namely renal injury, repair, potential recovery, or progression to long-term sequelae. These concepts are defined, and their underlying mechanisms outlined. Risk factors for progression are described, with discussion of clinical management priorities and potential future therapies aimed at minimizing long-term sequelae following AKI in children.

\section{Long-term sequelae of pediatric AKI}

Children have the potential to recover ostensibly normal kidney function following an episode of AKI, however a growing body of evidence suggests that chronic sequelae may be under-recognized. Over one-third of 176 children treated for AKI at a U.S. tertiary center had reduced kidney function, or remained dialysis dependent, at the time of discharge from hospital [8]. In the 3- to 5-year follow-up of this cohort, 17 of 29 children had long-term effects, including hyperfiltration, reduced kidney function, hypertension or proteinuria [9]. In another follow-up study of 126 children treated in intensive care, $10 \%$ had CKD within $1-3$ years following AKI [10]. A U.S. study of 63 pediatric heart transplant recipients with AKI showed that $5 \%$ of the patients had developed CKD at 12-month follow-up [11], and six of 37 children treated for AKI at a tertiary center in India had abnormal renal parameters at 10-year follow-up [12]. Infants who experience 
AKI in the neonatal period have an increased risk of abnormalities in kidney function in the long term [13, 14]. Taken together, these data demonstrate that recovery of normal kidney function following AKI in children is by no means guaranteed; pediatric AKI cannot be treated as an isolated event without due attention paid to the potential consequences.

Some children do recover their baseline kidney function following AKI, however understanding functional renal recovery in children is challenging for a number of reasons. Firstly, pediatric follow-up studies to date have not applied a standard definition of renal recovery, with definitions varying from dialysis independence during a hospital stay through to normalization of plasma creatinine, blood pressure and proteinuria. Secondly, the natural history of increasing glomerular filtration rate (GFR) in the first year of life from 15 to $90 \mathrm{ml} /$ $\min / 1.73 \mathrm{~m}^{2}$ presents challenges in defining baseline kidney function for infants. Thirdly, children have substantial renal reserve, so significant kidney damage resulting from an AKI episode can be compensated by hyperfiltration and may therefore not be reflected in the plasma creatinine level until adolescence or adulthood [15]. These challenges highlight the need to look beyond an operationalized definition of renal recovery based on functional measures, such as creatinine, in order to identify children who are at greatest risk of long-term sequelae following AKI. The identification of such children requires a deeper understanding of the sequence of events that follow an acute kidney insult, namely injury, repair and potential progression.

\section{The events that follow an acute kidney insult}

Until recently, progress in characterizing the events that follow an acute kidney insult was hampered by the lack of a consensus definition of progression and its associated events. Following recognition of this issue, a working group of the 13th Acute Dialysis Quality Initiative (ADQI) Conference sought to clarify these concepts. This group outlined a paradigm for understanding the clinical course of AKI and proposed definitions for terms related to events mediating resolution or progression [16]. They conceptualized the events that follow an acute kidney insult in three phases, as illustrated in Fig. 1. The development phase represents the immediate effects of the initial insult, which may be subclinical. The extension phase then ensues, in which both injury from the kidney insult and repair mechanisms compete. The resolution phase represents the net outcome of damage and repair. The duration of each phase can vary considerably depending on the nature of both the kidney insult and repair processes.

Concepts relating to progression following AKI are best understood in the context of the sequence of events described above. In the development phase, a kidney insult leads to injury. In the extension phase, repair processes are initiated in response to injury. Adaptive repair is a coordinated process, resulting in the resolution of renal structure without long-term sequelae. In contrast, maladaptive repair results in durable reduction in kidney function usually associated with a change in renal structure. The extension phase represents the net result of renal injury and repair processes. Renal recovery is a consequence of adaptive repair that leads to durable improvement in kidney function or structure. Conversely, progression is defined as a durable change in kidney structure or function detected by biomarkers, imaging studies or histopathology [16].

Recent progress has been made in operationalizing a definition of renal recovery; the Kidney Disease: Improving Global Outcomes (KDIGO) AKI work group developed the entity "acute kidney disease" to characterize partial functional recovery following AKI [5]. This was defined as a GFR of $<60 \mathrm{ml} / \mathrm{min} / 1.73 \mathrm{~m}^{2}$ or evidence of structural kidney damage for less than 3 months. This concept bridges the gap between the "Loss" and "End Stage" categories of the pediatric RIFLE criteria [17]. In clinical practice, recovery is often thought of as a return to baseline plasma creatinine. As discussed above, functional renal recovery should be interpreted with caution in children, as a return to baseline creatinine may mask underlying durable kidney damage.

\section{Pathophysiology of progression following AKI}

There is a growing understanding of the pathophysiologic mechanisms that underlie progression following AKI. Acute kidney insults disrupt tubules, capillaries and glomeruli, with the proximal tubule being particularly vulnerable [18]. Repair processes are then initiated in response to the insult $[19,20]$. Sustained recovery can be attributed to adaptive repair processes resulting from a well-balanced response between inflammatory and anti-inflammatory factors [21]. In many situations, this fine balance is not achieved, resulting in maladaptive repair, which predisposes to the development of interstitial fibrosis. Adaptive and maladaptive repair can be focally variable; tubular damage can resolve completely in some areas, whereas other areas can be less resilient to insults, leading to tubular atrophy. Maladaptive repair and interstitial fibrosis reduce the kidneys' reserve available to buffer further kidney insults. A negative spiral can then ensue, in which fibrotic damage further increases the risk of subsequent progression and more extensive chronic damage. The finely balanced response to the initial kidney insult, together with the nature and duration of this insult itself, are critical in determining the long-term outcome following AKI [7, 16, 22].

Animal models of AKI have led to the identification of a number of mechanistic pathways that contribute to progression following an acute kidney insult. These include oxidative stress, the DNA damage response pathway, epigenetic 
Fig. 1 The sequence of events following an acute kidney insult

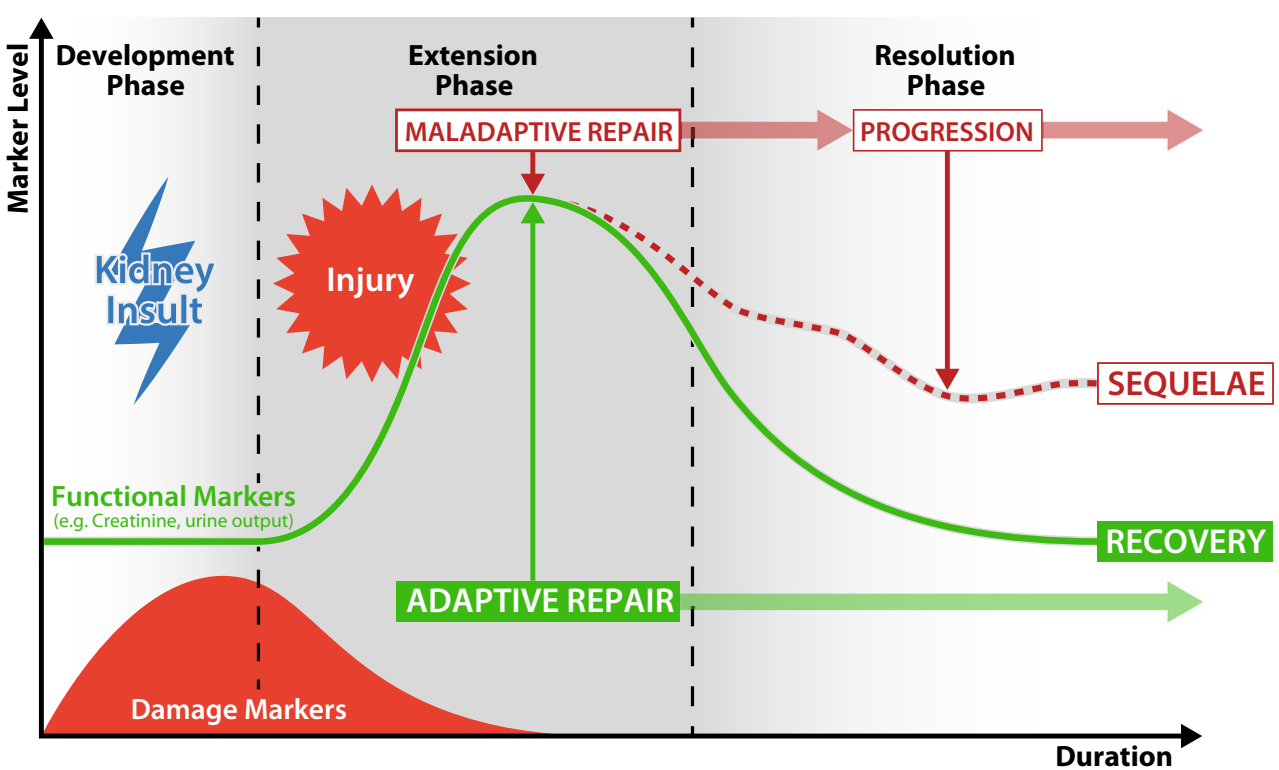

Emerging evidence suggests a role for complement pathways in progression following an acute kidney insult. Knockout of cell surface complement regulatory proteins from proximal tubular epithelial cells increases susceptibility to progressive injury in ischemia-reperfusion models of AKI $[35,36]$. Complement pathway inhibition ameliorates kidney injury in this model. Further work is needed to clarify the exact nature of complement interactions in AKI progression.

It is anticipated that growing knowledge of the mechanisms that underlie progression following AKI will ultimately lead to therapies that may ameliorate long-term sequelae, as discussed further in the section "Future therapies which may ameliorate progression following AKI".

\section{Identifying children who are at risk of progression following AKI}

The identification of children who are most at risk of progression following AKI is necessary in order to target interventions to minimize progression. Risk factors for long-term sequelae following AKI and techniques to stratify the risk of progression in children are outlined in this section.

The severity of a kidney insult is a well-established risk factor for progression following AKI. Insults that are severe and/or prolonged can disrupt the balance of inflammatory and anti-inflammatory factors required to facilitate adaptive repair processes, and thus compromise renal recovery [37, 38]. Multiple acute kidney insults exert a cumulative impact that can hamper adaptive repair and lead to sequelae. Laboratory and clinical observations support this concept. In animal models, the frequency of proximal tubule injury affects renal prognosis [38]. In adult patients with diabetes mellitus, repeated episodes of AKI are associated with end-stage renal disease 
Fig. 2 Pathophysiologic mechanisms of progression following acute kidney injury

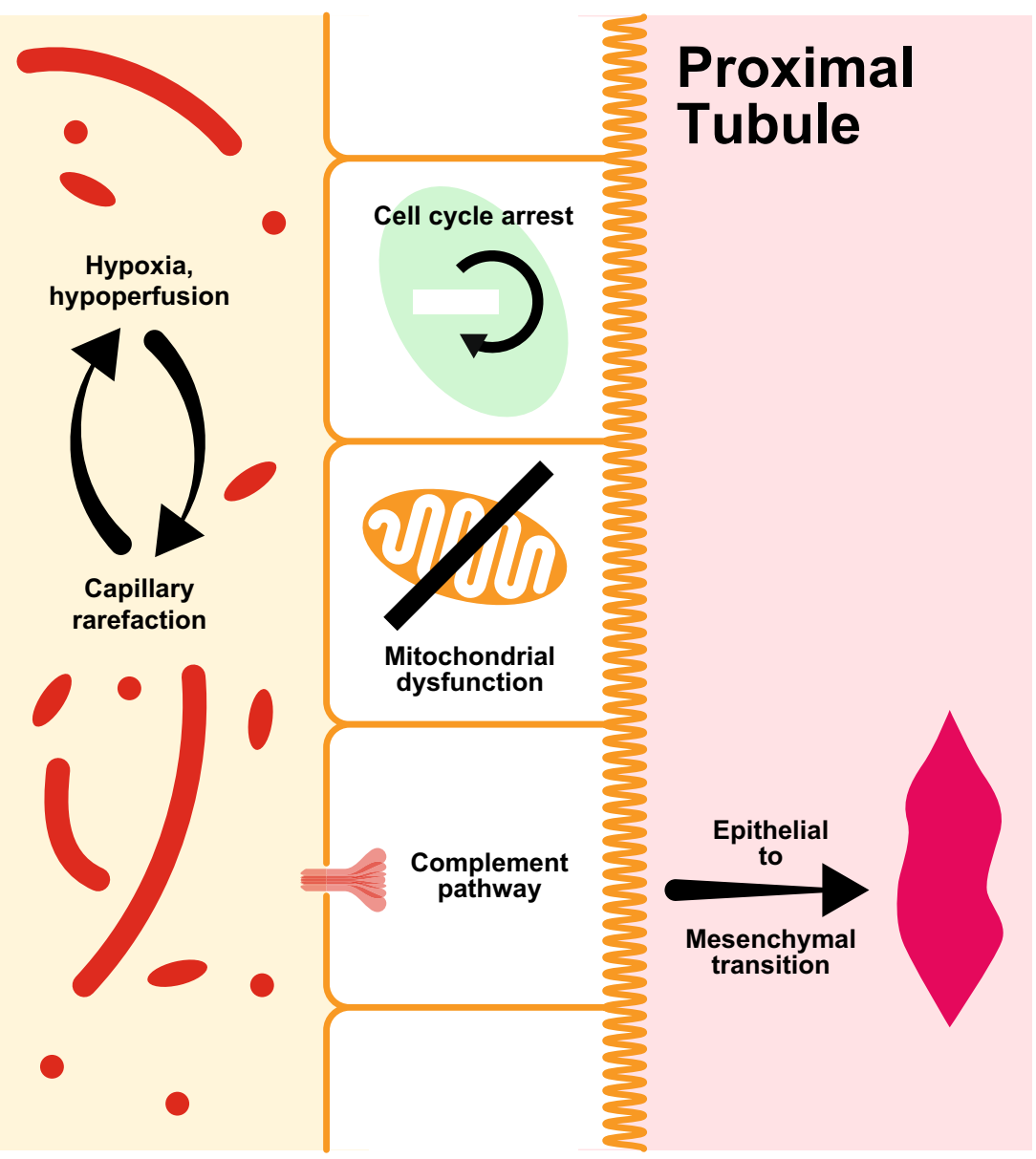

[39]. Multiple episodes of myohemoglobinuric AKI are closely associated with long-term kidney fibrosis and CKD [27]. The cumulative impact of multiple kidney insults can compromise adaptive repair processes with resultant progression.

Pre-existing CKD confers an increased risk of progression following AKI. Animal studies have demonstrated a propensity for maladaptive repair in the context of reduced renal mass [40]. Clinical studies in both adults and children evidence reduced capacity for functional renal recovery following AKI in patients with preexisting CKD [7, 22, 41, 42]. This phenomenon represents a high-risk to children with CKD given their lifetime exposure to acute kidney insults.

Many of the risk factors for progression outlined above are challenging to quantify. Strategies with greater discriminative power to identify children at risk of progression are needed. Large data techniques in which electronic health information, such as laboratory values, vital signs and patient characteristics, are used to build prediction models for events have been successfully used to stratify adult patients at risk of developing AKI [43]. Further work is needed to evaluate the application of these techniques to determine progression risk following $\mathrm{AKI}$ in both adults and children.
The use of urinary biomarkers to inform the risk of progression following AKI has shown some potential. In adult patients, three biomarkers have been found to predict progression of AKI among patients with acute cardiorenal syndrome, namely urinary angiotensinogen, urinary neutrophil gelatinase-associated lipocalin and urinary interleukin-18 [44]. Whilst studies in neonates and children with AKI have identified biomarkers with some discriminative value for the early identification of AKI [45-49], their use in risk stratification for progression has not been evaluated to date.

Imaging applications have shown promise in identifying features that may predict progression following AKI. Two magnetic resonance imaging (MRI) techniques, namely diffusion-weighted-MRI and blood oxygen level-dependentMRI, have been used to evaluate tubulointerstitial alterations and parenchymal hypoxia in patients with both AKI and CKD with some success [50]. Ultrasound and MRI elastography can provide hemodynamic and structural information which may be predictive of progression [51, 52]. Further evaluation of these non-invasive techniques may enhance assessment of progression risk in the future.

There is a clinical need to develop reliable strategies to stratify the risk of progression following AKI in the pediatric 
population in order to tailor appropriate therapy and follow up with the aim of minimizing long-term sequelae.

\section{Clinical strategies to minimize progression following AKI}

Strategies to minimize progression following AKI in children have not been systematically studied to date. Interventions should target removal of kidney insults and optimization of conditions that facilitate adaptive repair. Clinical priorities include optimization of kidney perfusion, removal of iatrogenic insults, attention to urinary drainage and correction of acidbase and electrolyte disturbances.

\section{Optimizing kidney perfusion}

Several factors underlie the kidneys' vulnerability to malperfusion after an acute insult. Autoregulation of renal blood flow can be disrupted, compounded by falling oxygen tension in the renal medulla which is already relatively hypoxic under normal physiologic conditions. Repair processes are particularly vulnerable to hypoxia in the context of tubulointerstitial edema, vasoconstriction, endothelial injury and capillary compression in AKI [37]. Impaired production of vasoactive factors by damaged tubules, such as vascular endothelial growth factor (VEGF), further compromise parenchymal perfusion [53]. Malperfusion hinders metabolically demanding adaptive repair processes.

Clinical observations in adult critical care patients support the key role of optimal renal perfusion in promoting adaptive repair following AKI. Both higher systemic oxygen delivery and higher mean arterial blood pressure are independently associated with a lower risk of sequelae following AKI [54]. However, the optimization of kidney perfusion can be clinically challenging in the context of generalized fluid overload in children. Key principles include the maintenance of adequate systemic blood pressure, with careful attention to the assessment and correction of intravascular volume depletion. Excessive or overrapid diuresis or ultrafiltation should be avoided. Inotropic support can be indicated, but there is no evidence to support the use of "renal dose" dopamine in AKI [55].

Novel therapies to reduce the impact of renal hypoperfusion on progression following AKI are on the horizon. These will be discussed further in the section "Future therapies which may ameliorate progression following AKI".

\section{Minimizing iatrogenic insults}

Persistent or repeated kidney insults hamper adaptive repair. In children with AKI, urgent evaluation of all factors that may compromise adaptive repair, as well as their removal, is therefore paramount.

A common iatrogenic kidney insult in the hospital setting is medication with nephrotoxic potential-in one study $86 \%$ of non-critically ill children were exposed to this risk [3]. Frequently prescribed agents include antibiotics, antifungals, antivirals, non-steroidal anti-inflammatory agents, immunosuppressants, intravenous contrast media and angiotensin-converting-enzyme inhibitors. A systematic screening program in hospitalized children was successful in reducing medication-related AKI, the main benefit being more rapid recognition, which led care teams to reduce medication exposure earlier [56]. This initiative was followed by a sustained quality improvement program which demonstrated a reduction in medication-related AKI over a 3-year period [57]. These studies were not designed to assess the effect of this strategy on progression following AKI, however it is intuitive that early removal of nephrotoxic insults might facilitate adaptive repair and limit progression.

\section{Optimizing urine drainage}

Relieving the urinary tract obstruction is a well-established management priority in AKI in both adults and children [6]. This is particularly important in children for whom congenital anomalies of the kidney and urinary tract (CAKUT) are a frequent cause of CKD. Children with CAKUT frequently experience episodes of AKI with acute-on-chronic impairment in kidney function. These episodes represent a high risk of progression. Renal tract dilatation should be evaluated using ultrasound [58], with optimization of urinary drainage in conjunction with a pediatric urologist and/or interventional radiologist if necessary. Delays in optimizing drainage can compromise adaptive repair.

\section{Controlling acid-base and electrolyte abnormalities}

Acid-base homeostasis can be severely disrupted following AKI. Processes such as proximal tubular bicarbonate reabsorption, distal tubular proton excretion and medullary urea recycling are compromised. Severe acidosis can compromise the coordination of adaptive repair by disrupting protein charge, conformation and function. In the clinical setting, controlling acid-base disturbance is likely to facilitate adaptive repair.

Electrolyte dysregulation is a further feature of AKI that can disrupt cellular function and thus hamper adaptive repair. Careful attention to plasma electrolyte levels and correction of gross abnormalities may therefore ameliorate progression.

Renal replacement therapy (RRT) may be necessary to control electrolyte and acid-base disturbance in children with oligo-anuric AKI. The optimal timing and modality of RRT to 
reduce the risk of progression have not yet been determined. In critically ill children, earlier initiation of continuous RRT may improve survival [59]. A key principle for the RRT prescription is avoidance of rapid or excessive ultrafiltration as this may compromise intravascular volume and renal perfusion, thus hampering adaptive repair.

\section{Future therapies which may ameliorate progression following AKI}

Whilst current clinical strategies to minimize progression focus on optimization of the microenvironment in order to facilitate adaptive repair, treatments to accelerate recovery are on the horizon. Potential targets for future therapies and their associated biochemical pathways are discussed in this section and summarized in Table 1.

A key pathway with future therapeutic potential is that of hypoxia and oxidative stress, both factors which can mediate progression [23, 24]. A number of relevant therapeutic targets have been identified. HIFs are transcription factors that play a key role in mediating cellular responses to hypoxia. In animal models of AKI, pre-ischemic targeting of the HIF pathway is effective in ameliorating injury and progression in specific circumstances $[26,60]$. Similarly, activation of Nrf2, a regulator of cellular resistance to oxidants, has shown promise in attenuating progression [61, 62]. Thirdly, exogenous VEGF, a stimulant of angiogenesis, can exert a protective effect on renal capillaries and ameliorate long-term damage following an acute insult [63]. The above targets have shown promise as potential future treatments that may minimize progression following hypoxic ischemic insults to the kidneys.

Mitochondrial dysfunction, which can result from AKI, presents an additional pathway relevant to progression. Suppression of mitochondrial biogenesis has been demonstrated in animal models of AKI [64] and is likely to promote progression to fibrosis through persistent cellular injury [65]. Therapeutic agents that support mitochondrial biogenesis and function may therefore be beneficial in ameliorating progression in the future.

Epigenetic changes can influence repair and progression following an acute kidney insult. Epigenetic alterations are activated after AKI and include histone modifications, DNA methylation and chromosomal conformational changes [16]. Novel therapeutic agents that target epigenetic alterations have shown promise in animal models of AKI; for example histone deacetylase inhibitors have been found to accelerate renal recovery and reduce fibrosis after AKI in zebrafish and mice [66].

The response of renal tubular epithelial cells to DNA damage is implicated in fibrosis of the kidney. Modifying the cell cycle of renal tubular epithelial cells via inhibition of tumor suppressor $\mathrm{p} 53$ and inhibiting downstream signaling from tubular cells in cell cycle arrest can prevent progression and fibrosis [67]. Further translational work is needed to determine if these strategies can ameliorate kidney fibrosis following $\mathrm{AKI}$ in the clinical setting.

Whilst the avenues discussed above hold promise for future accelerated adaptive repair in children at risk of AKI progression, they are all several steps away from being evaluated in the clinical setting. For now, the mainstays of clinical management to minimize progression remain optimization of renal perfusion, urinary drainage and the extracellular environment, and minimization of ongoing kidney insults.

\section{Summary}

Acute kidney injury is common in children treated in hospital, and a significant proportion experience long-term sequelae. Following AKI, adaptive repair processes can result in the recovery of kidney function; conversely, maladaptive repair can lead to progression, defined as a durable change in kidney

Table 1 Pathways of progression following acute kidney injury and related mechanisms and therapeutic targets

\begin{tabular}{|c|c|c|}
\hline Pathway & Mechanisms/model & Future therapies \\
\hline Oxidative stress & Capillary rarefaction & $\begin{array}{l}\text { Ischemic pre-conditioning } \\
\text { Activation of hypoxia-inducible factor (HIF) } \\
\text { Activation of nuclear factor erythroid 2-related factor } 2 \text { (Nrf2) } \\
\text { Exogenous vascular endothelial growth factor }\end{array}$ \\
\hline DNA damage response & $\begin{array}{l}\text { Aberrant cell cycle arrest } \\
\text { Endothelial to mesenchymal transition } \\
\text { Epithelial to mesenchymal transition } \\
\text { Pericyte to myofibroblast transition }\end{array}$ & p53 inhibitors \\
\hline Epigenetic changes & $\begin{array}{l}\text { Histone modifications } \\
\text { DNA methylation } \\
\text { Chromosomal conformational changes }\end{array}$ & Histone deacetylase inhibitors \\
\hline Mitochondrial dysfunction & $\begin{array}{l}\text { Suppression of mitochondrial biogenesis } \\
\text { Toll-like receptor 4-dependent mitogen activated protein kinase } \\
\text { Extracellular signal-regulated kinase signaling }\end{array}$ & Stimulators of mitochondrial biogenesis \\
\hline Complement & Cell surface complement regulatory protein knockout & Complement pathway blockade \\
\hline
\end{tabular}


structure or function detected by biomarkers, imaging studies or histopathology.

Established risk factors for progression include severity of the kidney insult, the cumulative impact of multiple AKI episodes and pre-existing CKD. Further risk stratification using electronic health record data, biomarker panels and imaging modalities are being evaluated.

Clinical strategies aimed at minimizing progression include optimization of kidney perfusion, urinary drainage and electrolyte and acid-base balance, as well as prompt removal of ongoing kidney insults. Future therapies that may accelerate adaptive repair following AKI and ameliorate progression are on the horizon.

\section{Multiple-choice questions (answers are provided following the references)}

1. Progression following AKI is defined as:

a) Increasing severity of acute kidney injury

b) Recovery of plasma creatinine to baseline

c) A durable change in kidney structure or function detected by biomarkers, imaging or histopathology

d) Extra-renal complications following AKI.

2. Following an acute kidney insult, which of the following are true?

a) Plasma creatinine may not change

b) injury initiates repair mechanisms

c) adaptive repair results in progression

d) progression can lead to chronic sequelae.

3. Risk factors for progression following AKI in children include:
a) Chronic kidney disease
b) Repeated episodes of AKI
c) Severity of the kidney insult
d) Interstitial fluid overload.

4. Clinical management priorities to reduce progression following AKI include:
a) Early angiotension-converting enzyme inhibition
b) Diuretic therapy
c) Optimizing kidney perfusion
d) All of the above.

5) Mechanistic pathways for future therapies include:
a) Oxidative stress
b) Cell cycle modification
c) Histone deacetylase inhibition
d) All of the above.

\section{Compliance with ethical standards}

Conflict of interest The author declares no conflict of interest.

Open Access This article is distributed under the terms of the Creative Commons Attribution 4.0 International License (http:// creativecommons.org/licenses/by/4.0/), which permits unrestricted use, distribution, and reproduction in any medium, provided you give appropriate credit to the original author(s) and the source, provide a link to the Creative Commons license, and indicate if changes were made.

\section{References}

1. Susantitaphong P, Cruz DN, Cerda J, Abulfaraj M, Alqahtani F, Koulouridis I, Jaber BL, Acute Kidney Injury Advisory Group of the American Society of Nephrology (2013) World incidence of AKI: a meta-analysis. Clin J Am Soc Nephrol 8(9):1482-1493

2. Sutherland SM, Ji J, Sheikhi FH, Widen E, Tian L, Alexander SR, Ling XB (2013) AKI in hospitalized children: epidemiology and clinical associations in a national cohort. Clin J Am Soc Nephrol 8(10):1661-1669

3. Moffett BS, Goldstein SL (2011) Acute kidney injury and increasing nephrotoxic-medication exposure in noncritically-ill children. Clin J Am Soc Nephrol 6(4):856-863

4. Lewington AJ, Cerda J, Mehta RL (2013) Raising awareness of acute kidney injury: a global perspective of a silent killer. Kidney Int 84(3):457-467

5. Kidney Disease: Improving Global Outcomes (KDIGO) Acute Kidney Injury Work Group (2012) KDIGO clinical practice guideline for acute kidney injury. Kidney Int Suppl 2:1-138

6. National Institute for Health and Clinical Excellence (NICE) (2013) Acute kidney injury: prevention, detection and management up to the point of renal replacement therapy. Guidance. Clinical guideline [CG169]. https://www.nice.org.uk/guidance/CG169.Accessed 8 Feb 2017

7. Chawla LS, Eggers PW, Star RA, Kimmel PL (2014) Acute kidney injury and chronic kidney disease as interconnected syndromes. N Engl J Med 371(1):58-66

8. Hui-Stickle S, Brewer ED, Goldstein SL (2005) Pediatric ARF epidemiology at a tertiary care center from 1999 to 2001. Am J Kidney Dis 45(1):96-101

9. Askenazi DJ, Feig DI, Graham NM, Hui-Stickle S, Goldstein SL (2006) 3-5 year longitudinal follow-up of pediatric patients after acute renal failure. Kidney Int 69(1):184-189

10. Mammen C, Al Abbas A, Skippen P, Nadel H, Levine D, Collet JP, Matsell DG (2012) Long-term risk of CKD in children surviving episodes of acute kidney injury in the intensive care unit: a prospective cohort study. Am J Kidney Dis 59(4):523-530

11. Hollander SA, Montez-Rath ME, Axelrod DM, Krawczeski CD, May LJ, Maeda K, Rosenthal DN, Sutherland SM (2016) Recovery from acute kidney injury and $\mathrm{CKD}$ following heart transplantation in children, adolescents, and young adults: a retrospective cohort study. Am J Kidney Dis 68(2):212-218

12. Sinha R, Nandi M, Tullus K, Marks SD, Taraphder A (2009) Tenyear follow-up of children after acute renal failure from a developing country. Nephrol Dial Transplant 24(3):829-833

13. Abitbol CL, Bauer CR, Montane B, Chandar J, Duara S, Zilleruelo G (2003) Long-term follow-up of extremely low birth weight infants with neonatal renal failure. Pediatr Nephrol 18(9):887-893

14. Askenazi DJ, Ambalavanan N, Goldstein SL (2009) Acute kidney injury in critically ill newborns: what do we know? What do we need to learn? Pediatr Nephrol 24(2):265-274 
15. Goldstein SL (2014) Renal recovery at different ages. Nephron Clin Pract 127(1-4):21-24

16. Basile DP, Bonventre JV, Mehta R, Nangaku M, Unwin R, Rosner MH, Kellum JA, Ronco C, ADQI XIII Work Group (2016) Progression after AKI: understanding maladaptive repair processes to predict and identify therapeutic treatments. J Am Soc Nephrol 27(3):687-697

17. Akcan-Arikan A, Zappitelli M, Loftis LL, Washburn KK, Jefferson LS, Goldstein SL (2007) Modified RIFLE criteria in critically ill children with acute kidney injury. Kidney Int 71(10):1028-1035

18. Chevalier RL (2016) The proximal tubule is the primary target of injury and progression of kidney disease: role of the glomerulotubular junction. Am J Physiol Ren Physiol 311(1): F145-F161

19. Humphreys BD, Valerius MT, Kobayashi A, Mugford JW, Soeung S, Duffield JS, McMahon AP, Bonventre JV (2008) Intrinsic epithelial cells repair the kidney after injury. Cell Stem Cell 2(3):284 291

20. Bonventre JV, Yang L (2011) Cellular pathophysiology of ischemic acute kidney injury. J Clin Invest 121(11):4210-4221

21. Rabb H, Griffin MD, McKay DB, Swaminathan S, Pickkers P, Rosner MH, Kellum JA, Ronco C, Acute Dialysis Quality Initiative Consensus XIII Work Group (2016) Inflammation in AKI: current understanding, key questions, and knowledge gaps. J Am Soc Nephrol 27(2):371-379

22. Venkatachalam MA, Griffin KA, Lan R, Geng H, Saikumar P, Bidani AK (2010) Acute kidney injury: a springboard for progression in chronic kidney disease. Am J Physiol Ren Physiol 298(5): F1078-F1094

23. Kim J, Seok YM, Jung KJ, Park KM (2009) Reactive oxygen species/oxidative stress contributes to progression of kidney fibrosis following transient ischemic injury in mice. Am J Physiol Ren Physiol 297(2):F461-F470

24. Basile DP, Leonard EC, Beal AG, Schleuter D, Friedrich J (2012) Persistent oxidative stress following renal ischemia-reperfusion injury increases ANG II hemodynamic and fibrotic activity. Am J Physiol Ren Physiol 302(11):F1494-F1502

25. Igarashi G, Iino K, Watanabe H, Ito H (2013) Remote ischemic preconditioning alleviates contrast-induced acute kidney injury in patients with moderate chronic kidney disease. Circ J 77(12):30373044

26. Matsumoto M, Makino Y, Tanaka T, Tanaka H, Ishizaka N, Noiri E, Fujita T, Nangaku M (2003) Induction of renoprotective gene expression by cobalt ameliorates ischemic injury of the kidney in rats. J Am Soc Nephrol 14(7):1825-1832

27. Nath KA, Croatt AJ, Haggard JJ, Grande JP (2000) Renal response to repetitive exposure to heme proteins: chronic injury induced by an acute insult. Kidney Int 57(6):2423-2433

28. Basile DP, Donohoe D, Roethe K, Osborn JL (2001) Renal ischemic injury results in permanent damage to peritubular capillaries and influences long-term function. Am J Physiol Ren Physiol 281(5):F887-F899

29. Basile DP (2007) The endothelial cell in ischemic acute kidney injury: implications for acute and chronic function. Kidney Int 72(2):151-156

30. Ma Z, Wei Q, Dong G, Huo Y, Dong Z (2014) DNA damage response in renal ischemia-reperfusion and ATP-depletion injury of renal tubular cells. Biochim Biophys Acta 1842(7):1088-1096

31. Yang L, Besschetnova TY, Brooks CR, Shah JV, Bonventre JV (2010) Epithelial cell cycle arrest in G2/M mediates kidney fibrosis after injury. Nat Med 16(5):535-543, 1p following 143

32. Basile DP, Friedrich JL, Spahic J, Knipe N, Mang H, Leonard EC, Changizi-Ashtiyani S, Bacallao RL, Molitoris BA, Sutton TA (2011) Impaired endothelial proliferation and mesenchymal transition contribute to vascular rarefaction following acute kidney injury. Am J Physiol Ren Physiol 300(3):F721-F733
33. Liu Y (2010) New insights into epithelial-mesenchymal transition in kidney fibrosis. J Am Soc Nephrol 21(2):212-222

34. Humphreys BD, Lin SL, Kobayashi A, Hudson TE, Nowlin BT, Bonventre JV, Valerius MT, McMahon AP, Duffield JS (2010) Fate tracing reveals the pericyte and not epithelial origin of myofibroblasts in kidney fibrosis. Am J Pathol 176(1):85-97

35. Miao J, Lesher AM, Miwa T, Sato S, Gullipalli D, Song WC (2014) Tissue-specific deletion of Crry from mouse proximal tubular epithelial cells increases susceptibility to renal ischemia-reperfusion injury. Kidney Int 86(4):726-737

36. Brar JE, Quigg RJ (2014) Complement activation in the tubulointerstitium: AKI, CKD, and in between. Kidney Int 86(4): 663-666

37. Venkatachalam MA, Weinberg JM, Kriz W, Bidani AK (2015) Failed tubule recovery, AKI-CKD transition, and kidney disease progression. J Am Soc Nephrol 26(8):1765-1776

38. Takaori K, Nakamura J, Yamamoto S, Nakata H, Sato Y, Takase M, Nameta M, Yamamoto T, Economides AN, Kohno K, Haga H, Sharma K, Yanagita M (2016) Severity and frequency of proximal tubule injury determines renal prognosis. J Am Soc Nephrol 27(8): 2393-2406

39. Sabbisetti VS, Waikar SS, Antoine DJ, Smiles A, Wang C, Ravisankar A, Ito K, Sharma S, Ramadesikan S, Lee M, Briskin R, De Jager PL, Ngo TT, Radlinski M, Dear JW, Park KB, Betensky R, Krolewski AS, Bonventre JV (2014) Blood kidney injury molecule-1 is a biomarker of acute and chronic kidney injury and predicts progression to ESRD in type I diabetes. J Am Soc Nephrol 25(10):2177-2186

40. Polichnowski AJ, Lan R, Geng H, Griffin KA, Venkatachalam MA, Bidani AK (2014) Severe renal mass reduction impairs recovery and promotes fibrosis after AKI. J Am Soc Nephrol 25(7):14961507

41. Hsu CY (2012) Yes, AKI truly leads to CKD. J Am Soc Nephrol 23(6):967-969

42. James MT, Hemmelgarn BR, Wiebe N, Pannu N, Manns BJ, Klarenbach SW, Tonelli M, Alberta Kidney Disease Network (2010) Glomerular filtration rate, proteinuria, and the incidence and consequences of acute kidney injury: a cohort study. Lancet 376(9758):2096-2103

43. Koyner JL, Adhikari R, Edelson DP, Churpek MM (2016) Development of a multicenter ward-based AKI prediction model. Clin J Am Soc Nephrol 11(11):1935-1943

44. Chen C, Yang X, Lei Y, Zha Y, Liu H, Ma C, Tian J, Chen P, Yang $\mathrm{T}$, Hou FF (2016) Urinary biomarkers at the time of AKI diagnosis as predictors of progression of AKI among patients with acute cardiorenal syndrome. Clin J Am Soc Nephrol 11(11):1536-1544

45. Askenazi DJ, Koralkar R, Patil N, Halloran B, Ambalavanan N, Griffin R (2016) Acute kidney injury urine biomarkers in very low-birth-weight infants. Clin J Am Soc Nephrol 11(9):1527-1535

46. Vijayan A, Faubel S, Askenazi DJ, Cerda J, Fissell WH, Heung M, Humphreys BD, Koyner JL, Liu KD, Mour G, Nolin TD, Bihorac A, American Society of Nephrology Acute Kidney Injury Advisory Group (2016) Clinical use of the urine biomarker [TIMP-2] $\times$ [IGFBP7] for acute kidney injury risk assessment. Am J Kidney Dis 68(1):19-28

47. Menon S, Goldstein SL, Mottes T, Fei L, Kaddourah A, Terrell T, Arnold P, Bennett MR, Basu RK (2016) Urinary biomarker incorporation into the renal angina index early in intensive care unit admission optimizes acute kidney injury prediction in critically ill children: a prospective cohort study. Nephrol Dial Transplant 31(4): 586-594

48. McCaffrey J, Coupes B, Chaloner C, Webb NJ, Barber R, Lennon $R$ (2015) Towards a biomarker panel for the assessment of AKI in children receiving intensive care. Pediatr Nephrol 30(10):18611871 
49. Basu RK, Wang Y, Wong HR, Chawla LS, Wheeler DS, Goldstein SL (2014) Incorporation of biomarkers with the renal angina index for prediction of severe AKI in critically ill children. Clin J Am Soc Nephrol 9(4):654-662

50. Inoue $\mathrm{T}$, Kozawa $\mathrm{E}$, Okada $\mathrm{H}$, Inukai $\mathrm{K}$, Watanabe $\mathrm{S}$, Kikuta $\mathrm{T}$, Watanabe Y, Takenaka T, Katayama S, Tanaka J, Suzuki H (2011) Noninvasive evaluation of kidney hypoxia and fibrosis using magnetic resonance imaging. J Am Soc Nephrol 22(8):1429-1434

51. Grenier N, Merville P, Combe C (2016) Radiologic imaging of the renal parenchyma structure and function. Nat Rev Nephrol 12(6): 348-359

52. Korsmo MJ, Ebrahimi B, Eirin A, Woollard JR, Krier JD, Crane JA, Warner L, Glaser K, Grimm R, Ehman RL, Lerman LO (2013) Magnetic resonance elastography noninvasively detects in vivo renal medullary fibrosis secondary to swine renal artery stenosis. Investig Radiol 48(2):61-68

53. Tanaka S, Tanaka T, Nangaku M (2014) Hypoxia as a key player in the AKI-to-CKD transition. Am J Physiol Renal Physiol 307(11): F1187-1195

54. Raimundo M, Crichton S, Syed Y, Martin JR, Beale R, Treacher D, Ostermann M (2015) Low systemic oxygen delivery and BP and risk of progression of early AKI. Clin J Am Soc Nephrol 10(8): $1340-1349$

55. Dunning J, Khasati N, Barnard J (2005) Low dose (renal dose) dopamine in the critically ill patient. Interact Cardiovasc Thorac Surg 3(1):114-117

56. Goldstein SL, Kirkendall E, Nguyen H, Schaffzin JK, Bucuvalas J, Bracke T, Seid M, Ashby M, Foertmeyer N, Brunner L, Lesko A, Barclay C, Lannon C, Muething S (2013) Electronic health record identification of nephrotoxin exposure and associated acute kidney injury. Pediatrics 132(3):e756-e767

57. Goldstein SL, Mottes T, Simpson K, Barclay C, Muething S, Haslam DB, Kirkendall ES (2016) A sustained quality improvement program reduces nephrotoxic medication-associated acute kidney injury. Kidney Int 90(1):212-221

58 Faubel S, Patel NU, Lockhart ME, Cadnapaphornchai MA (2014) Renal relevant radiology: use of ultrasonography in patients with AKI. Clin J Am Soc Nephrol 9(2):382-394

59 Modem V, Thompson M, Gollhofer D, Dhar AV, Quigley R (2014) Timing of continuous renal replacement therapy and mortality in critically ill children*. Crit Care Med 42(4):943-953

60 Kapitsinou PP, Jaffe J, Michael M, Swan CE, Duffy KJ, EricksonMiller CL, Haase VH (2012) Preischemic targeting of HIF prolyl hydroxylation inhibits fibrosis associated with acute kidney injury. Am J Physiol Ren Physiol 302(9):F1172-F1179

61 Liu M, Reddy NM, Higbee EM, Potteti HR, Noel S, Racusen L, Kensler TW, Sporn MB, Reddy SP, Rabb H (2014) The Nrf2 triterpenoid activator, CDDO-imidazolide, protects kidneys from ischemia-reperfusion injury in mice. Kidney Int 85(1): 134-141

62 Wu J, Liu X, Fan J, Chen W, Wang J, Zeng Y, Feng X, Yu X, Yang X (2014) Bardoxolone methyl (BARD) ameliorates aristolochic acid (AA)-induced acute kidney injury through Nrf2 pathway. Toxicology 318:22-31

63 Leonard EC, Friedrich JL, Basile DP (2008) VEGF-121 preserves renal microvessel structure and ameliorates secondary renal disease following acute kidney injury. Am J Physiol Ren Physiol 295(6): F1648-F1657

64 Smith JA, Stallons LJ, Collier JB, Chavin KD, Schnellmann RG (2015) Suppression of mitochondrial biogenesis through toll-like receptor 4-dependent mitogen-activated protein kinase kinase/ extracellular signal-regulated kinase signaling in endotoxininduced acute kidney injury. J Pharmacol Exp Ther 352(2):346-357

65 Stallons LJ, Whitaker RM, Schnellmann RG (2014) Suppressed mitochondrial biogenesis in folic acid-induced acute kidney injury and early fibrosis. Toxicol Lett 224(3):326-332

66 Cianciolo Cosentino C, Skrypnyk NI, Brilli LL, Chiba T, Novitskaya T, Woods C, West J, Korotchenko VN, McDermott L, Day BW, Davidson AJ, Harris RC, de Caestecker MP, Hukriede NA (2013) Histone deacetylase inhibitor enhances recovery after AKI. J Am Soc Nephrol 24(6):943-953

67 DiRocco DP, Bisi J, Roberts P, Strum J, Wong KK, Sharpless N, Humphreys BD (2014) CDK4/6 inhibition induces epithelial cell cycle arrest and ameliorates acute kidney injury. Am J Physiol Ren Physiol 306(4):F379-F388 